\title{
Perkembangan Wawasan Dan Praksis (Termasuk Metode) Misi Abad Ke-19 Sampai Dengan Medio Abad Ke-20 Dalam Perjumpaannya Dengan Agama Dan Budaya Masyarakat Pribumi
}

\author{
Abialtar \\ Sekolah Tinggi Teologi Moriah Gading Serpong \\ abialtar@gmail.com
}

Abstract: This research was conducted by the author to find out and produce qualitative data regarding the development of mission insights and praxis from the 19th century to the 20th century in the context of their encounter with indigenous peoples' religions and cultures within the scope of the Mamasa Toraja Church.

Keywords: Insights, Missiology, Mamasa Toraja Church

Abstrak: Penelitian ini dilakukan oleh penulis untuk mengetahui dan menghasilkan data kualitatif perihal perkembangan wawasan dan praksis misi abad ke-19 dengan abad ke-20 dalam konteks perjumpaannya dengan agama dan budaya massyarakat pribumi dalam lingkup pelayanan Gereja Toraja Mamasa.

Kata Kunci: Wawasan, Misiologi, Gereja Toraja Mamasa

\section{Pendahuluan}

Jumlah pekabar Injil pada abad ke-19 dan 20 meningkat tajam. Sekitar 100.000 misionaris dari Protestan maupun Katolik. Hampir tidak ada negeri atau daerah yang tidak diinjili. ${ }^{1}$ Hal itu disebabkan oleh pertambahan penduduk Eropa dan Amerika yang pesat, dibarengi perkembangan teknologi perhubungan, telekomunikasi, percetakan dan militer yang semakin maju, sehingga membuka peluang imperialisme dan juga misi. Jadi, imperialisme dan misi adalah "saudara sekandung".

Tulisan ini akan mengulas masing-masing satu contoh pekabaran Injil di Indonesia dan di Asia (di luar Indonesia) oleh para misionaris yang diutus oleh badan-badan zending tertentu, untuk mengetahui perkembangan wawasan dan praksis (termasuk metode) misi mereka dalam perjumpaannya dengan agama dan budaya masyarakat pribumi. Untuk itu, penulis akan meneliti sejarah zending Protestan di Mamasa, Sulawesi Barat dan juga di

1 Th. van den End, Sejarah Gereja Asia, cet. II (Yogyakarta: PPIP Dutawacana, 1988), 59. 
India untuk mengetahui bagaimana strategi, metode dan wawasan para tenaga zending ${ }^{2}$ dalam memberitakan Injil ketika berjumpa dengan konteks daerah dan negara yang dipilih tersebut. Penulis tidak akan membahas semua pekabar Injil yang ada di daerah dan negara yang dipilih tetapi hanya memilih beberapa penginjil saja. Penulis mengakui keterbatasannya dalam mencapai maksud judul tulisan ini. Oleh karena itu, kritik dan masukan dari para pembaca sangat diharapkan demi perbaikan ke depan.

\section{Metode Penelitian}

Pada penelitian ini, penulis atau peneliti menggunakan pendekatan atau metode kualitatif untuk memperoleh data yang valid guna membangun sebuah teori yang berkaitan dengan tema atau pokok penelitian. Metode kualitatif yang dimaksud adalah mengkaji dan mengelaborasi setiap sumber, informasi dan data-data yang diperoleh dari pustaka.

\section{Hasil dan Pembahasan}

\section{Pekabaran Injil Di Mamasa Sulawesi Barat}

Pada mulanya, Gubernur Sulawesi memberi kepercayaan kepada Gereformeerde Zendingsbond (GZB) untuk menginjil di seluruh wilayah Sulawesi Selatan, termasuk di Tana Toraja (Toraja Sa'dan) dan Toraja Barat (Mamasa). Tetapi karena keterbatasan dana GZB, maka mereka hanya menginjil di Toraja Sa'dan, sedangkan pihak Indische Kerk/Gereja Protestan Indonesia (GPI) mengutus Pdt. R. W. Kyftenbelt mengijil di daerah Mamasa dan sekitarnya. Itulah sebabnya, maka sejak tahun 1913 GPI telah bekerja di Mamasa (Toraja Barat). ${ }^{3}$ Ia membaptis banyak orang tanpa pemberian pokok-pokok ajaran Kristen, sekaligus membuka sekolah-sekolah dan mendatangkan guru-guru dari Ambon dan Maluku. Guru-guru dimaksud adalah Daud Raranta, Azarja Sahetapy, Markus Sahuleka dan Abraham Sahulata. ${ }^{4}$

Pada tahun 1913, dibangun 6 sekolah di Mamasa, masing-masing di desa Mamasa, Nosu, Pakin, Rante Walian dan Orobua. Sekolah-sekolah tersebut disubsidi oleh

2 A. de Kuiper mengatakan bahwa istilah-istilah "(usaha) pekabaran Injil", "pengutusan" dan "tugas yang menjadi makna pengutusan" merupakan terjemahan kata tunggal dalam bahasa Belanda, yaitu zending (Th. van den End, Sumber-sumber Zending tentang Sejarah Gereja Kristen Sumba 1859-1972 (terj.) (Jakarta: BPK Gunung Mulia, 1996, h. 125). Jan S. Aritonang mengatakan, istilah Misi umumnya untuk Katolik (catatan atas laporan buku III konsentrasi 2 penulis, September 2013).

3 W. A. van der Klies, Datanglah Kerajaan-Mu: Limah Puluh Tahun Pekabaran Injil di Toraja Barat 19131969 (Rantepao: Sulo, 2006), 13: "Sejak tahun 1900 situasi di Mamasa tidak stabil karena perang antar daerah dan juga hubungan dengan masyarakat daerah dataran rendah (kerajaan Mandar dan Bugis) sering tidak baik. Raja-raja dataran rendah selalu berusaha menguasai hasil bumi daerah Mamasa sedangkan orang Mamasa mengayau (membunuh dan mengambil kepala) orang di daerah dataran rendah. Pada waktu itu, banyak orang Mamasa yang dijadikan budak oleh raja-raja dataran rendah." (Pengayauan adalah rangkaian ritual Pa'totiboyongan).

4 Ibid., 13. 
pemerintah. ${ }^{5}$ Adapun motivasi pemerintah kolonial Belanda ${ }^{6}$ dan GPI menginjil di Mamasa adalah menghindari pengaruh masyarakat dataran rendah (khususnya Mandar) yang beragama Islam melalui perdagangan dan perkawinan. Menurut mereka, upaya kristenisasi di Mamasa akan mendukung stabilitas sosial politik. Gubernur Sulawesi, W.J. Coenen (1910-1913), juga berpendapat demikian. ${ }^{7}$

Di mana-mana pendeta GPI ini disambut baik oleh masyarakat Mamasa, ${ }^{8}$ tetapi mereka dibaptis bukan karena pertobatan yang murni melainkan karena takut kepada pemerintah kolonial. Mereka berkata:

Kami tidak tahu apa maksud kedatangan tuan ini (penginjil GPI) tetapi kami kira bahwa ini kehendak pemerintah. Dan karena kami baru-baru diselamatkan dari penindasan dan pemerasan orang-orang Bugis, maka kami taat, walaupun secara tersembunyi sebelum dan setelah acara (baptisan) kami membawa persembahan kepada roh-roh nenek moyang pada upacara Pali Tomate (upacara pemakaman) untuk memohon ampun karena kami menghina mereka dengan menyerahkan diri di bawah kuk asing dan bersedia dibaptis. ${ }^{9}$

Kutipan di atas membuktikan bahwa pada waktu itu penginjil GPI di satu pihak telah menyadari peran serta pemerintah dalam PI, tetapi di pihak lain mengabaikan peranan kebudayaan masyarakat pribumi dan pengajaran Kristen bagi yang akan dibaptis. Oleh karena itu, banyak orang Kristen di Mamasa beralih ke Alu' Toyolo pada masa pendudukan Jepang, bahkan ada juga yang masuk Islam. ${ }^{10}$ Status GPI sebagai gereja negara tentu tidak boleh melepaskan diri dari aturan dan kebijakan negara sehingga kuasa, wibawa dan pemerintah kolonial dibawa serta oleh mereka dalam memberitakan Injil. Oleh karena itu, orang masuk Kristen karena ketaatan kepada pemerintah bukan semata-mata kepada Allah. Van den End mengatakan, akibat status itu, “GPI tidak boleh menyelenggarakan sekolah-sekolah, apalagi mengabarkan Injil di kalangan orang-orang yang bukan

5 Ibid., 22.

6 Ibid., 14: "Dalam rangka "politik pasifikasi”, seluruh Sulawesi Selatan ditempatkan di bawah pemerintahan kolonial Belanda sejak 1905. Pada 25 mei 1907, serdadu Belanda masuk daerah Mamasa. Selama beberapa tahun rakyat Mamasa kadang-kadang memberontak tetapi mereka tidak mampu mengusir serdadu Belanda tersebut."

7 Ibid.

8 Van der Klies, op.cit., 22.

${ }^{9}$ Deputaten voor de Zending der Christelijke Gereformeerde Kerken Nederland, Pergilah Kamoe! Gaat dan Heen!: Geschiedenis van de Buitenlandse Zending der Christelijke Gereformeerde Kerken Nederland tot 1959 (Dodrecht: D. J. van Brummen, 1960), 73.

${ }^{10}$ Hengky Gunawan, "Kepemimpinan GTM abad XXI" (ceramah, Aula BPMS-GTM, Mamasa, 8 Juli 2011). 
Kristen."11 Walaupun demikian, peran GPI sangat besar dan menentukan dalam mendasari lahirnya kekristenan di Toraja Barat sebelum badan zending lain datang.

Pada tahun 1928, de Christelijke Gereformeerde Kerken (CGK), sebuah gereja Calvinis konservatif kecil di Belanda, mengambil alih tanggung jawab penginjilan di wilayah Toraja Barat. Serah terima daerah Mamasa sebagai lapangan zending dari GPI kepada CGK dilakukan pada saat GPI mengalami banyak kesulitan di Mamasa. Oleh karena itu, seorang pendeta bantu yang ditempatkan di Mamasa, Van Dalen, menganggap penting adanya badan zending yang bertanggungjawab di Mamasa. Atas persetujuan pendeta GPI di Makassar, G. C. A. A. van den Wijngaard dan controleur (Petor) Mamasa, R. H. Mulder, penyerahan Mamasa dari pengurus GPI kepada Ds. Arie Bikker sebagai perwakilan CGK, dilaksanakan pada 1 Januari 1928. ${ }^{12}$

Badan zending CGK, Zending van de Christelijke Gereformeerde Kerken (ZCGK) mengutus pekabar Injil mereka, Pdt. Arie Bikker dan Pdt. Marthin Geleijnse ke Mamasa. Bikker tiba di Mamasa tahun 1927 dan Geleijnse baru menyusul, dua tahun kemudian, 1929. Bikker ditempatkan di pos pI Mamasa dan Geleijnse di pos pI Pitu Ulunna Salu (PUS). Pada statistik tahun 1932, dilaporkan jumlah orang Kristen di Mamasa 1.338 orang, dan lainnya kembali ke Alu' Toyolo. Hal ini terjadi karena mereka kecewa dengan sikap penginjil CGK pada awal pelayanan mereka yang berusaha menyederhanakan adat istiadat dan kebudayaan masyarakat pribumi, seperti yang dilakukan oleh GPI.13

Bikker dan Geleijnse mempunyai sikap yang berbeda dalam perjumpaan mereka dengan kebudayaan Mamasa. Di pos pI PUS, Geleijnse berusaha memisahkan kebudayaan dan ritus Alu' Toyolo dari kekristenan seperti yang dilaporkan oleh Deputat ZCGK sebagai berikut:

Di kampung itu berdiri pohon barana (pohon beringin) yang selalu dipakai untuk bermacam-macam ritual Alu' Toyolo. Waktu itu, orang Bulo menjadi Kristen sehingga semua berhala dan alat-alat sihir dibakar dibawah pohon itu. Pohon barana itu ditebang di satu meter tingginya. Dengan demikian, dilambangkan bahwa kebenaran firman Tuhan menang atas orang kafir. Kemudian gedung gereja akan dibangun sekelilingnya. ${ }^{14}$

11 Th. van den End \& J. Weitjens, Ragi Carita 2: Sejarah Gereja di Indonesia, cet. ke-3 (Jakarta: BPK Gunung Mulis, 1999), 51.

12 Van der Klies, op.cit., 31: "Daerah misi yang diserahkan kepada Zending van de Christelijke Gereformeerde Kerken (ZCGK) meliputi afdeling Mandar dan afdeling Pare-Pare yang dibagi atas dua bagian besar, yaitu onderafdeling Boven-Binoeng dan Pitoe Ulunna Saloe (PUS) dengan lebih dari 40.000 penduduk. Kemudian distrik Kalumpang di onderafdeling Mamoedjoe dengan sekitar 8.000 penduduk, distrik LembangLembang di onderafdeling Pinrang dengan sekitar 5.500 penduduk dan daerah yang didiami mayoritas Muslim meliputi onderafdeling Madjene, Polewali, Pinrang, Enrekang, Pare-Pare, Rappang dan Barru."

${ }^{13}$ Abialtar, Katekismus Heidelberg di Gereja Toraja Mamasa: Menyoal Kontekstualisasi Katekismus Heidelberg dalam Konteks Pergumulan Budaya dan Oikumenis Gereja Toraja Mamasa (STT Jakarta: Tesis M.Th., 2008), 108.

14 Deputaten voor de Zending der Christelijke Gereformeerde Kerken Nederland, Pergilah Kamoe! Gaat dan Heen!, op.cit., 128. 
Pembakaran atribut-atribut kepercayaan Alu' Toyolo oleh Geleijnse adalah simbol dari pemusnahan adat istiadat dan kepercayaan nenek moyang. Seorang tokoh adat di Mamasa mengatakan, "menebang dan membakar pohon beringin dan benda-benda di sekitarnya dilarang karena di situlah kepercayaan kami dilestarikan turun temurun. Tuan Geleijnse telah berusaha mencabut kebudayaan lama dan ingin menggantikan dengan kebudayaan baru. Ia tidak menyadari kesulitan dan kemustahilan memaksakan kebudayaan Barat kepada kami."15 Sikap seperti itu pada akhirnya akan membuat masyarakat Kristen di daerah PUS menjadi orang asing tanpa akar dan tanpa tempat berakar. Kebudayaan, termasuk ritus-ritus Alu' Toyolo dianggap sebagai hal yang harus dimusnahkan, padahal kebudayaan adalah ciptaan Tuhan dan dapat menjadi sarana untuk memberitakan injil melalui dialog dengan masyarakat setempat.

Sementara itu, Bikker melakukan metode lain dalam menghadapi kebudayaan masyarakat di pos pI (pekabaran Injil) Mamasa, seperti kutipan berikut ini:

Tanggal 15 Juli 1937 merupakan hari istimewa dalam sejarah penginjilan di Mamasa. Pada waktu itu, berkumpullah 3.000 orang di gedung gereja lama (gedung sekolah). Waktu itu diadakan pertemuan bersama antar para Parenge (kepala distrik) dari Mamasa, Osango, Tawalian dan Orobua. Hadir juga Parenge Malabo dan Parenge Tandung, controleur (petor) Mamasa, bapak H. J. van Schravendijk, semua guru, majelis gereja serta hampir seluruh kepala kampung dan kepala adat. Pada pertemuan itu, diadakan dialog dan percakapan antara orang Kristen dengan penganut Alu' Toyolo. Penganut Alu' Toyolo mengungkapkan keberatan-keberatan mereka terhadap kehadiran agama Kristen di Mamasa. Mereka kuatir kebudayaan mereka yang berhubungan dengan adat istiadat, khususnya dalam hal kematian dihilangkan. Pertemuan itu dimulai kira-kira pukul 10.00 pagi sampai dengan pukul 19.00 malam dan banyak orang yang mau masuk agama Kristen setelah dialog dilaksanakan. Parenge Osango berpidato menyatakan secara terbuka bahwa dia sudah masuk agama Kristen disusul oleh Parenge lainnya kecuali Parenge Tawalian, karena sebelumnya sudah Kristen. Sebagai tanda kesatuan para Parenge masuk Kristen, maka akan didirikan sebuah batu sebagai tanda kesatuan mereka dalam agama Kristen. Pendirian batu adalah tradisi Alu' Toyolo untuk mengukuhkan sebuah perjanjian. Pendirian batu peringatan itu akan dilaksanakan bersamaan dengan peletakan batu pertama gedung gereja di Mamasa tanggal 31 Juli 1937. Pada tanggal 31 Juli 1937 jam 10.00 pagi, pertemuan dimulai untuk peletakan batu pertama gedung gereja itu dan pendirian batu peringatan kesatuan para Parenge masuk agama Kristen. Acara itu dihadiri oleh asisten residen Mandar W. J. Leyds dan controleur Mamasa H. J. van Schravendijk. Hadir semua kepala distrik, kepalakepala kampung dan banyak kepala adat dan semua orang Kristen di pos pI Mamasa. Saya (Bikker) mengkhotbahkan Yosua 24:15b dan 18b yang menekankan bagaimana Yosua mendirikan sebuah batu supaya mereka tidak melupakan janjinya kepada Tuhan. Sesudah khotbah, semua hadirin pergi ke lokasi pendirian gedung gereja, diatas bukit. Di sana didirikan juga batu bersegi empat. Pada setiap sisi batu 
itu ditulis masing-masing nama keempat distrik lembah Mamasa, yaitu distrik Osango, Mamasa, Tawalian dan Orobua. Sekeliling batu itu diikat dengan tali. Pada tali itu diikat lagi tali-tali yang panjang dan dibentangkan ke semua arah. Keempat Parenge masing-masing berdiri di segi batu itu sesuai dengan nama distrik mereka. Di belakang masing-masing Parenge berdiri rakyat mereka yang akan menyaksikan kesatuan pemimpin mereka dalam kepercayaan Kristen. Saya mengucapkan doa semoga Allah Yang Maha Kuasa memberkati gedung gereja supaya boleh menjadi tempat keselamatan dan damai sejahtera. Saya meminta kepada semua Parenge untuk meletakkan tangannya di atas batu itu dan kepada mereka yang berdiri dibelakang Parenge masing-masing diminta supaya dengan tangan kirinya memegang tali yang diikat pada batu itu. Hal itu menyimbolkan kesatuan mereka. Selanjutnya, saya membacakan 1 Petrus 5:10-11 kemudian secara bersama-sama menyanyikan Mazmur 99:1,2,8. Gedung gereja Mamasa mulai digunakan pada 29 Desember 1938 dan dinamakan Gereja Beatrix. Beatrix adalah nama dari salah seorang ratu kerajaan Belanda yang lahir pada tahun 1938. Di pintu gedung gereja itu tertulis "Ia melepaskan kaoemNya daripada segala dosanja" (Matius 1:21). ${ }^{16}$

Jadi, salah satu metode penginjilan Bikker adalah mengedepankan dialog dan menghargai atribut kebudayaan masyarakat setempat. Ia melibatkan tokoh-tokoh adat dan pemerintah untuk bersatu mendukung pekerjaannya. Ia tidak gegabah menghilangkan benda-benda yang erat hubungannya dengan kepercayaan Alu' Toyolo, melainkan mengambil alih fungsi benda tersebut (batu) untuk pengukuhan janji para tokoh masyarakat setempat untuk menganut agama Kristen. Jadi, sikap Bikker lebih menghargai budaya setempat dan meyakini bahwa kebudayaan dapat menjadi sarana ampuh dalam pI. Bikker telah berhasil menyadarkan pemerintah, khususnya para Parenge akan fungsi dan peranan mereka dalam mendukung penginjilan. Tetapi pemerintah juga tidak boleh mencampuri urusan gereja terlalu jauh.

Metode dialog dalam pI terus dikembangkan oleh Bikker untuk pos pI PUS di mana Geleijnse menginjil, seperti contoh berikut ini:

Pada bulan Juni 1929, di daerah Bamban terjadilah rapat di rumah Parenge pada minggu malam. Hadir pada waktu itu ratusan orang, penganut Alu' Toyolo, para imam, pemimpin-pemimpin adat dan sebagian orang Kristen. Setelah Bikker berbicara, terjadilah debat antara orang Kristen dan Alu' Toyolo. Salah seorang pemimpin Alu' Toyolo berbicara bahwa adat mereka sangat baik dan berwibawa. Tetapi kepala kampung Galung-Galung yang bernama Manggasa (nama Kristennya Jakob) menentang kepala adat tersebut di atas dengan bertanya: "Dapatkah engkau melakukan semua ketentuan adat itu?" Mungkin engkau mengenal 700 larangan tetapi mampukah bapak melakukan itu semua? Dan masih ada 7.000 larangan lagi yang kamu tidak kenal. Tidakkah engkau mendengar bahwa tenaga penginjilan kita ini berbicara bahwa ada jalan lain untuk diselamatkan. Bahwa anak Allah telah datang untuk mengalahkan iblis dan kuasanya untuk menebus kita dari kuk para roh-roh. Tetapi engkau ingin tetap duduk dalam penjara." Pertemuan tersebut berlangsung sampai dengan malam hari dan hasilnya sangat besar. Di kampung Tabulahan ada 42 anak muda mengaku imannya. Di Taora, semua orang ikut kelas

16 Deputaten voor de Zending der Christelijke Gereformeerde Kerken Nederland, op.cit., 128-133. 
katekisasi. Akibat dari kelas katekisasi itu maka banyak dari mereka yang mampu menjawab pertanyaan-pertanyaan sekitar sejarah Alkitab, Sepuluh Hukum Tuhan, Doa Bapa Kami, dan 12 Pengakuan Iman Rasuli. ${ }^{17}$

Kutipan di atas juga adalah dialog yang dipimpin oleh Bikker tetapi yang berdialog selanjutnya adalah pemimpin Alu' Toyolo dengan seorang kepala kampung yang sudah Kristen. Kepala kampung "menang" dalam dialog tersebut sekaligus mewakili pihak penginjil. Jadi, dalam dialog semacam itu, masyarakat pribumi yang lebih paham kebudayaannya bertindak sebagai penginjil dan sangat relevan pada waktu itu.

Sama seperti penginjil Eropa di daerah lain pada abad ke-19, pembukaan sekolah zending tetap merupakan strategi dan metode yang mampu membuka wawasan pribumi untuk kritis terhadap adat istiadat dan kebudayaan serta kepercayaan mereka dan akhirnya menerima agama Kristen. Para penginjil menyadari pentingnya dialog untuk mengetahui isi hati masyarakat yang diwakili oleh pihak pemerintah, pemuka agama pribumi dan tokoh-tokoh masyarakat pribumi lainnya.

Wawasan dan metode termasuk praksis penginjil CGK dalam perjumpaan konteks masyarakat pribumi Mamasa mengalami perkembangan setelah melihat dan memahami kebudayaan dan adat istiadat masyarakat setempat. Pada tahun 1947, deputat CGK mengirim lagi tenaga penginjil yang ketiga dan keempat yaitu J. van Dalen dan G.H. Polman. Van Dalen dan istrinya tiba di Mamasa pada tanggal 17 Juli 1947 dan dua tahun kemudian, bulan Januari 1949 G.H. Polman juga tiba di Mamasa. Penginjil van Dalen mengadakan banyak perkunjungan ke daerah-daerah pedalaman bersama istrinya yang berprofesi sebagai perawat kesehatan sehingga mereka menolong banyak orang sakit. Penginjil G.H. Polman bersama istrinya lebih banyak mengurus administrasi pI, terutama keuangannya, dan membuka kursus kepemimpinan perempuan. ${ }^{18}$ CGK telah melangkah lebih maju lagi dengan memperhatikan kebutuhan jasmani masyarakat setempat terutama kesehatan dan kepedulian terhadap kaum perempuan. Di Mamasa perempuan memegang peranan penting karena perempuan juga mengambil bagian dalam ritus keagamaan. Perempuan boleh menjadi imam Alu' Toyolo (sando baine) yang bertugas dalam ritual Pa'titoboyongan. Dengan demikian, ketika perempuan dirangkul oleh penginjil maka tidak ada penolakan dari pemuka adat dan masyarakat pribumi.

17 Deputaten voor de Zending der Christelijke Gereformeerde Kerken Nederland, op.cit., 92-93

18 Van der Klies, Datanglah Kerajaan-Mu: Limah Puluh Tahun Pekabaran Injil di Toraja Barat 19131963, op.cit., 107-108. 
Perhatian dan pelayanan CGK terhadap kaum perempuan semakin meningkat setelah mereka mengutus Ny. M. Bakker Klomp sebagai tenaga pelayan sosial bagi kaum perempuan di Mamasa pada tanggal 17 Juli 1947. Nyonya M. Bakker Klomp menyelenggarakan banyak pembinaan tentang bagaimana seorang ibu rumah tangga mengurus rumah tangganya dan peran perempuan dalam kepemimpinan. Pokok-pokok pembinaan nyonya Klomp antara lain menjaga kebersihan badan, rumah, pakaian dan sebagainya untuk mencegah bermacam-macam penyakit. Selain itu, Nyonya M. Bakker Klomp membuka Sekolah Kepandaian Putri (Huishoudschool) untuk memberikan kursuskursus kepada kelompok-kelompok perempuan yang terpilih agar mereka boleh langsung menerapkan hasil kursus itu dikampungnya masing-masing.

Di bidang kesehatan, CGK mendirikan Rumah Sakit Banua Mamase di Mamasa pada tahun193919. Biaya pendirian dan penyelenggaraan rumah sakit itu diperoleh dari pemerintah Celebes sebesar 3.500 Gulden setiap tahun. Dari SIMAVI (sebuah organisasi bantuan medis) diperoleh bantuan dana sebesar 2.000 Gulden per tahun selama 3 tahun. Deputat CGK juga diminta membuat aksi pengumpulan dana untuk pembangunan rumah sakit, sehingga dalam waktu singkat terkumpullah dana sebesar 10.000 gulden dan dengan dana itu, pembangunan rumah sakit dapat dimulai dan pada bulan Oktober 1939, pembangunan rumah sakit tersebut rampung dan mulai dioperasikan pada 31 Oktober 1939.20

Tenaga dokter pertama yang bersedia bertugas di Rumah Sakit tersebut adalah Dr. P.R. Rotty. Rotty adalah tamatan STOVIA (Sekolah Dokter Indonesia) di Jakarta dan telah bekerja selama 28 tahun di pelbagai tempat di Indonesia. Setelah melewati tantangan berat pada masa pendudukan Jepang, akhirnya Gereja Mamasa, Gereja Toraja Mamasa (GTM) lahir secara resmi pada proto-Sinode, tanggal 4-7 Juni 1947 yang dihadiri oleh penginjil Geleijnse dan Bikker. Pada tahun 1954 ada lebih dari 20.000 orang dibaptis dan pada akhir tahun 1955 jumlah warga GTM menjadi 30.623 jiwa. ${ }^{21}$ GTM menjadi anggota DGI (sekarang PGI) pada tanggal 25 Mei 1950.22

\section{PEKABARAN INJIL INDIA}

Pekabaran Injil Protestan di India datang bersamaan dengan penjajahan Inggris. Oleh karena itu, keduanya dianggap satu oleh bangsa India. Pakar sejarah India, K.M. Panikkar,

\footnotetext{
${ }^{19}$ Deputaten voor de Zending der Christelijke Gereformeerde Kerken Nederland, Pergilah Kamoe! Gaat dan Heen!, 139.

20 Ibid.

21 Van der Klies, Datanglah Kerajaan-Mu, 117.

22 Persekutuan Gereja-gereja di Indonesia, Buku Almanak Kristen Indonesia 2013 (Jakarta; Bidang Kononia PGI, 2013), 292.
} 
menyebut imperialisme sebagai "penyokong dan sekutu gereja". 23 Misionaris di India yang menjadi pelopor gelombang baru misi Protestan adalah William Carey (1761-1834) yang ditahbiskan sebagai pendeta Gereja Baptis pada tahun 1785 merangkap tukang sepatu dan guru sekolah. Ia gemar membaca buku dan mempelajari bahasa. Ia juga belajar tentang misi di Tranquebar, tentang John Elliot, dan misi Moravian (Herrnhut). ${ }^{24}$ Puncak pengaruh Carey terhadap penginjilan sedunia adalah ketika ia menerbitkan karangannya: "An Enquiry in to the Obligation of Christians to Use Means for the Conversion of the Heathens" pada tahun 1792. Dalam karangan itu, Carey menolak pandangan umum mengenai Protestantisme saat itu bahwa Amanat Agung dalam Matius 28:18-20 hanya berlaku bagi para Rasul. Menurut Carey, Amanat tersebut masih berlaku sampai sekarang ${ }^{25}$ dan untuk semua orang percaya kepada Kristus. Kecakapan Carey antara lain kemadiriannya dalam belajar bahasa seperti bahasa Latin, Yunani dan Ibrani. Bahasa-bahasa ini sangat penting dalam menafsirkan Alkitab dan juga sejarah dan pengakuan gereja. Kepandaian Carey dan keterampilan praktis yang dimiliki sangat mendukung dalam penginjilannya di India. ${ }^{26}$

Pada tahun 1793, Baptist Missionary Society (BMG) ${ }^{27}$ mengutus Carey sekeluarga ke India sebagai penginjil pertama badan misi tersebut. Tetapi karena perusahaan perdagangan Inggris, East India Company (EIC) yang ada di India melarang penginjilan, ${ }^{28}$ maka untuk sementara, Carey beralih pekerjaan, yaitu pengelola pabrik nila di pedalaman India. Tetapi pekerjaan Carey yang baru malah menjadi suatu strategi dalam persiapan pekabaran Injil di India. Ia menggunakan kesempatan itu untuk belajar bahasa Sanskrit dan bahasa Bengali di India, sehingga ia kemudian berhasil menerjemahkan hampir seluruh Alkitab ke dalam bahasa Bengali, walaupun terjemahan yang pertama masih sulit dipahami. Walaupun demikian, usaha Carey menerjemahkan Alkitab ke dalam bahasa

${ }^{23}$ Anne Ruck, Sejarah Gereja Asia (Jakarta: BPK Gunung Mulia, 1997), 119.

${ }^{24}$ Klaus Wetzel, Kompendium Sejarah Gereja Asia (Malang: Gandum Mas, 2000), 192.

25 Ibid., 193.

${ }^{26}$ Anne Ruck, Sejarah Gereja Asia., 120.

27 Klaus Wetzel, Kompendium Sejarah Gereja Asia,195: “Pada tanggal 30 Mei 1792, pada kesempatan Konferensi Para Pendeta (Sinode Gereja Baptis), Carey berkhotbah tentang Yesaya 54:2-3 dengan kesimpulan: "Haraplah hal-hal yang besar dari Allah: berusahalah melakukan hal-hal yang besar bagi Allah." Sebagai hasil khotbah tersebut lembaga misi Baptis (Baptist Missionary Society) didirikan pada bulan Oktober 1792. Atas pengaruh Carey dan kawan-kawannya maka pada th 1795 didirikanlah London Missionary Society oleh pihak Congregationalis, menyusul Church Missionary Society oleh kaum Anglican. Lembaga-lembaga ini didirikan oleh golongan evangelikal (orang-orang yang menekankan pertobatan pribadi dan atas kesucian hidup sesudahnya)."

28 Van den End, Sejarah Gereja Asia, 58:" Penginjilan dilarang jika "negara" itu adalah suatu badan pedagangan (VOC atau EIC) karena melihat kepentingan perdagangan. Jika agama yang disebarkan itu menguntungkan, ia didukung; kalau merugikan, ditentang." 
setempat merupakan metode yang strategis dalam rangka memperkenalkan agama Kristen kepada penduduk pribumi.

Carey memprioritaskan penerjemahan Alkitab ke dalam bahasa setempat setelah bergabung lalu bekerjasama dengan pekabar Injil lainnya, Joshua Marshman (1768-1873) dan William Ward (1764-1823) yang tiba di Serampore, dekat Calcutta, tahun 1799.29 Dalam waktu 30 tahun ketiga pekabar Injil tersebut, yang dikenal dengan "Serampore Trio", berhasil menerjemahkan Alkitab ke dalam 6 bahasa, ditambah bagian-bagian tertentu dari Alkitab diterjemahkan ke dalam 26 bahasa, walaupun masih bersifat sementara dan belum sempurna. Penerjemahan Alkitab selanjutnya dengan mutu yang lebih baik dilakukan pada saat Henry Martyn (1781-1810) dari Gereja Anglikan datang di India dan bekerjasama dengan Serampore Trio, sehingga Perjanjian Baru dalam bahasa Urdu telah siap dicetak pada tahun 1810 dan masih tetap dipakai sebagai dasar bagi penerjemahan hingga menjelang akhir abad ke-20.30

Selain menerjemahkan Alkitab, Carey juga menganggap penelitian agama dan kebudayaan India sebagai tugas misi yang tidak boleh diabaikan. Oleh karena itu, ia menyusun buku tata bahasa Sanskrit, bahkan menerjemahkan Ramayana ke dalam bahasa Inggris. Atas kerjasama Serampore Trio dalam penginjilan, maka pada tahun 1800 seorang India dibaptis di Serampore, yang ditetapkan sebagai pusat pelayanan Baptis dan William Ward menjadi pendeta di sana. ${ }^{31}$ Selain mencintai dan meneliti kebudayaan India, Carey pun mengadakan perkunjungan ke pedesaan di India sambil mendirikan pos-pos penginjilan di tepi sungai Gangga di Orissa. Bahkan ia sampai ke Burma untuk mencapai tujuan mendirikan gereja asli India yang mandiri secepat mungkin. Kemandirian gereja di lapangan misi sesuai dengan hukum Gereja Baptis yang menekankan kemandirian setiap jemaat.

Selanjutnya, Carey mendirikan sekolah-sekolah termasuk perguruan tinggi (Serampore College) pada tahun 1819 di Serampore yang kemudian ditingkatkan menjadi universitas yang juga mengajarkan teologi Kristen, filsafat India, dan ilmu pengetahuan Barat. ${ }^{32}$

Pelayanan sosial dan ekonomi turut diperhatikan oleh Carey. Oleh karena itu, ia mendirikan Horticultural Society (Lembaga llmu Perkebunan) dengan tujuan meningkatkan metode-metode pertanian, termasuk mengimpor pohon buah-buahan dari Inggris. Carey juga mengadakan percobaan dengan tanaman kopi, tembakau, gula tebu dan

29 Ibid., 121.

30 Ruck, Sejarah Gereja Asia., 123.

31 Ibid., 122.

32 Ibid., 122. 
tanaman yang menghasilkan biji-bijian. ${ }^{33}$ Bahkan ia mendirikan Kebun Raya di Serampore yang menjadi termasyur di seluruh Asia. ${ }^{34}$ Dapat disimpulkan bahwa asas-asas penginjilan Carey adalah penelitian kebudayaan India, penginjilan seluas-luasnya, penerjemahan Alkitab, serta pendirian gereja mandiri dengan tenaga rohani asli pribumi. Asas-asas penginjilan tersebut sekaligus menjadi ciri khas misi Protestan. ${ }^{35}$

Konteks India yang paling menantang pekabaran Injil, baik dari Protestan maupun Katolik, adalah sistem kasta sebagai inti pokok kebudayaan mereka. Kitab suci Veda menggambarkan empat golongan utama, yakni Brahmana (imam dan pemikir), Raja atau kesatria (penguasa), Vaisya (pedagang, petani, tukang) dan Syudra (buruh, pekerja, tukang sederhana). Selain pembagian kasta, ada banyak perbedaan lain menurut keturunan dan pekerjaan dan setiap kasta mempunyai fungsi dan peranan dalam keseluruhan masyarakat India. ${ }^{36}$ Carey menganggap sistem kasta sebagai hal yang tidak dapat dipisahkan dari agama Hindu. Carey menyesuaikan diri sejauh mungkin dengan kebudayaan India dalam segala hal yang tidak langsung bertentangan dengan Firman Tuhan. Misalnya orang yang menjadi Kristen tidak diwajibkan menceraikan istri kedua, namun tidak boleh memegang jabatan gereja kecuali kalau mempunyai satu istri saja. Tetapi Carey tegas menuntut agar orang yang baru percaya keluar dari kastanya dan sengaja membuat dirinya najis, misalnya menyentuh kulit binatang, sebagai lambang menolak kepercayaan lama. ${ }^{37}$

Jadi, perkembangan wawasan dan metode Carey, mewakili badan misi Gereja Baptis, terjadi seiring dengan tingkat pemahamannya terhadap kebudayaan India. Kecintaannya terhadap budaya India sangat mempengaruhi metode menghadapi kebudayaan pribumi. Carey memahami budaya sebagai hal yang tidak kebetulan ada, sebab kebudayaan adalah ciptaan juga. Berbeda dengan Carey, Daniel Wilson, uskup Anglikan di Calcutta (1833-1858), dengan keras menyalahkan sistem kasta sebagai semacam penyakit kanker dalam gereja yang harus langsung diserang dan dilenyapkan. Orang Kristen adalah satu dan tidak bisa dipisahkan satu dengan yang lain. Oleh karena itu, Wilson menyuruh orang Kristen India mengikuti sakramen Perjamuan Kudus secara bersama-sama tanpa pembagian kasta seperti yang diterapkan oleh misi Denmark/Halle yang juga menyesuaikan diri dengan sistem kasta. ${ }^{38}$

\footnotetext{
33 Ibid.

34 Van den End, Sejarah Gereja Asia, 63.

35 Ruck, Sejarah Gereja Asia, 123.

36 Ibid., 125.

37 Ibid.

38 Ibid.
} 
Dalam menghadapi pertobatan massal (mass-movements) di India, Carey sebagai pekabar Injil dari kalangan Pietis/Revival dan evangelikal tentu merupakan suatu persoalan. Di satu sisi dia harus menanam gereja (church planting), tetapi di sisi lain ia harus menekankan kesungguhan pertobatan, bukan karena mengikuti kepala suku atau komunal mereka yang sekasta. Mungkin pendirian Serampore College dan penerjemahan Alkitab ke dalam beberapa bahasa di India merupakan solusi Carey dalam memelihara rohani masyarakat India, khususnya dari golongan kasta rendah yang dibaptis.

Wetzel $^{39}$ menyimpulkan bahwa ada lima prinsip pelayanan yang dikembangkan oleh William Carey, yakni: pekabaran Injil disebarkan seluas-luasnya dengan memakai metode apapun, menerjemahkan Alkitab ke dalam bahasa setempat sebanyak mungkin, mendirikan jemaat-jemaat yang dapat mandiri secepat mungkin, melaksanakan penelitian tentang kebudayaan, agama dan bahasa setempat, dan mendirikan seminari untuk mendidik pendeta pribumi.

Van den End ${ }^{40}$ merumuskan 4 asas usaha pekabaran Injil Carey, sebagai berikut:

1. Pemberitaan Injil yang langsung dengan berjalan keliling dan menyebarkan Injil di ratusan desa di sekitar Serampore.

2. Penyebaran Alkitab dalam bahasa setempat ( 6 bahasa di India) dan menerbitkan buku-buku gramatika dan kamus-kamus.

3. Pelajaran yang sedalam mungkin tentang latar belakang dan dunia pemikiran pribumi. Carey menerjemahkan sendiri Ramayana ke dalam bahasa Inggris (jadi tidak menganjurkan "one-way traffic" dari Barat ke Timur saja). Dalam kurikulum Serampore College yang didirikan Carey, tidak hanya vak-vak Alkitabiah dan Theologia Kristen saja yang ada, tetapi juga agama dan filsafat India; dan orangorang yang bukan Kristen disambut juga sebagai murid.

4. Secepat mungkin harus didirikan suatu Gereja yang bersifat mandiri. Asas ini sesuai dengan hukum Gereja Baptis, yang menekankan kemerdekaan jemaat setempat.

Van den End menyimpulkan bahwa Carey mempunyai visi yang lebih luas daripada kebanyakan pekabar Injil sesudahnya.41 Carey diperlengkapi dengan dua kemampuan, yaitu intelektualisme dan keberanian serta iman yang kuat sehingga wawasan dan metode penginjilannya berkembang sesuai dengan konteks dan kebutuhan masyarakat India pada waktu itu.

39 Wetzel, Kompendium Sejarah Gereja Asia, 195-196.

40 Van den End, Sejarah Gereja Asia, 63.

41 Ibid. 
Akan tetapi, perkembangan wawasan BMG lebih nyata ketika Alexander Duff (1806-1878) tiba di India pada tahun 1830 menggantikan Carey. Ia merespons kritik-dari Inggris dan masyarakat Eropa pada umumnya terhadap cara kerja pekabar Injil sebelumnya di India yang hanya membaptis sedikit masyarakat India dan dari golongan kasta tinggi. ${ }^{42}$ Oleh karena itu, Duff berusaha mencapai lapisan atas masyarakat India dengan mendirikan lembaga-lembaga perguruan tinggi dengan mempergunakan bahasa Inggris sebagai bahasa pengantar. Duff bermaksud mentransfer ilmu pengetahuan Barat kepada masyarakat India melalui anak-anak para bangsawan yang kelak akan menjadi pemimpin yang beragama Kristen. Duff berharap bahwa dengan golongan pemimpin yang baru itu serentak seluruh kebudayaan India akan menjadi Kristen. Di samping itu, Duff juga memajukan pendidikan bagi kaum wanita India. ${ }^{43}$

Pekabar Injil lainnya di India adalah William Miller (1838-1923) yang wawasannya lebih positif terhadap kebudayaan Hindu. Tujuannya bukan untuk menggantikan kebudayaan Hindu dengan kebudayaan Kristen Barat, melainkan supaya kebudayaan Hindu diresapi nilai-nilai Kristen agar muncul suatu kebudayaan Hindu-Kristen, yang mempertahankan ciri-ciri khasnya sendiri terhadap Barat.

\section{ANALISIS DAN REFLEKSI KRITIS}

Latar belakang maraknya penginjilan abad ke-19 dan ke-20, selain kemajuan teknologi (disebut pada bagian pendahuluan), juga munculnya suatu gerakan rohani yang dikenal dengan sebutan Pietisme/Revivalisme pada abad ke-17 dan ke-18 di kalangan Protestan-di Eropa Barat. Pietisme/Revivalisme dilatarbelakangi oleh ketidakpuasan terhadap kehidupan kerohanian gereja yang menjadi suam dan khotbah-khotbah yang intelekstualistis. Pemberitaan gereja hanya memuaskan otak saja tetapi tidak memuaskan batin jemaat.

Gerakan itu menekankan kesalehan pribadi dan penghayatan iman Kristen dalam seluruh bidang kehidupan. Gerakan Pietisme juga memasuki Belanda, lalu disebut nadere reformatie (reformasi lebih lanjut) yang dibawa oleh orang-orang Herrnhut dan berujung pada pembentukan Perhimpunan Pekabaran Injil (De Broedersocieteit tot Uitbreiding van het Evangelie onder de Heidenen - Lembaga Persaudaraan untuk Perluasan Injil di Kalangan

\footnotetext{
42 Ibid., 65.
}

43 Ibid., 66. 
Orang Kafir). ${ }^{44}$ Tujuan perhimpunan pI ini adalah memajukan persaudaraan (ekumenis) ${ }^{45}$ untuk menjadi saksi Kristus, memberitakan Injil kepada bangsa-bangsa yang belum mengenal Kristus. ${ }^{46}$ Selanjutnya, berdirilah lembaga-lembaga misi lainnya pada abad ke19, antara lain, Evangelical Alliance (Perserikatan Injili) di London (1864), Young Men's/Women's Christian Association (YMCA/YWCA) (1855), dll.

Badan zending yang menginjil di Mamasa tentu berlatarbelakang De Broedersocieteit tot Uitbereiding van het Evangelie onder de Heidenen itu. Oleh karena itu, istilah yang dikenakan bagi masyarakat pribumi yang belum Kristen adalah orang kafir atau penyembah berhala. Di Mamasa, banyak penganut Alu' Toyolo yang keberatan disebut orang kafir (bahasa Mamasa: to kape) karena mereka juga meyakini menyembah dewa yang berkuasa dan menolong umat-Nya. ${ }^{47}$ Selain latar belakang di atas, asas-asas zending Gereformeerd yang ditetapkan pada Sinode Middelburg (1896) ${ }^{48}$ juga mempengaruhi wawasan dan metode para penginjil, khususnya di Mamasa dan Sumba. Asas-asas dimaksud terdiri atas: tujuan penginjilan, siapa yang mengutus?, siapakah yang hendak diutus?, kepada siapa mereka diutus?, dengan cara bagaimana pekabaran Injil harus dijalankan?, dan hubungan zending . ${ }^{49}$ Tujuan penginjilan menurut asas-asas ini adalah memuliakan Allah melalui usaha pI terhadap orang-orang yang akan binasa. Jadi, penilaian gereja dan badan zending-nya terhadap orang yang beragama lain pada waktu itu bersifat eksklusif, sehingga para penginjil sangat antusias dan militan menginjil di mana pun di pelosok daerah jajahan Belanda. Mereka hanya memperhatikan perintah (Allah) dan tidak mengindahkan hasilnya, itulah yang harus tetap merupakan pedoman seluruh usah pI tersebut. ${ }^{50}$ Perintah $\mathrm{pI}$ itu diambil dari teks Alkitab terpilih, misalnya dan yang paling utama adalah Matius 28:18-20, sehingga defenisi misi pada abad ke-19 adalah pengiriman misionaris, kegiatan misionaris, penyebaran agama Kristen, pertobatan orang kafir, dan pendirian jemaat baru.

Definisi-definisi pekabaran Injil yang paralel satu dengan yang lain di atas dapat dikatakan sebagai yang tradisional dan banyak dipakai oleh pekabar Injil gereja-gereja Barat dan biasa disebut "a classical western theology framework". 51 Pada umumnya, wawasan penginjil pada abad ke-19 tentang kebudayaan pribumi masih sangat sempit

${ }^{44}$ H. Berkhof dan I.H. Enklaar, Sejarah Gereja (Jakarta: BPK GM, 1991), 254.

45 Th. van den End, Harta dalam Bejana (Jakarta: BPK Gunung Mulia, cet. ke-17 2004), 386.

46 J.L. Ch. Abineno, Kraemer di Tambaram (Jakarta: BPK Gunung Mulia, 1988), 3-4.

47 Ambe Mahine (pemimpin Aluk Toyolo), wawancara dengan penulis, Mamasa, 18 Juli 2012.

48 Van den End, Sumber-sumber Zending..., 141.

49 Ibid., 141-149.

50 Ibid., 142.

${ }^{51}$ Kim Kirsten, Missiology as Global Conversation of (Contextual) Theologies (STT Jakarta: Artikel Bahan Test Kualifikasi S-3, 2012), 4. 
sehingga kebudayaan itu dianggap sebagai kebudayaan kafir. Selain itu, menurut Charles van Engen, ada tiga faktor yang tampak secara simultan membentuk perspektif misi seseorang, yaitu: pesan Alkitab (teks Alkitab), pandangan tentang gereja sebagai umat Allah (komunitas umat beriman), dan konteks misi gereja di dunia. ${ }^{52}$ Menurut Dean S. Gilliland, pengalaman pribadi (latar belakang budaya, pergumulan dan pergulatan serta spiritualitas personal) dan pandangan dunia seseorang adalah dua faktor lain yang turut mempengaruhi pandangan misi seseorang. ${ }^{53}$ Dalam pengertian ini, maka sebuah paradigma yang terintegrasi dalam pandangan seseorang atau kelompok orang dalam menggeluti misi gereja dapat dikatakan dipengaruhi oleh lima faktor tersebut. Sementara itu, pusat integrasi dari paradigma misi terletak pada Yesus Kristus yang merupakan sumber (kepala) misi gereja. ${ }^{54}$

Faktor lainnya adalah sikap "menghakimi”, bahkan ingin menyederhanakan bahkan meniadakan kebudayaan masyarakat pribumi. Padahal kebudayaan, termasuk kebudayaan Barat, sebagaimana disebutkan oleh Louis Lutzbetak, adalah pola hidup (design for living) yang membuat kehidupan bermakna. ${ }^{55}$ Berbicara tentang kebudayaan berarti kita berbicara mengenai persekutuan manusia dalam komunitasnya dan dalam hubungan dengan Allah. ${ }^{56}$ Memang, daya tarik kebudayaan sering tampaknya lebih kuat daripada daya tarik Injil Yesus Kristus. ${ }^{57}$ Oleh karena itu, perlu ada pedoman dan pegangan agar penghayatan yang kontekstual dan relevan menjadikan Injil suatu kuasa yang menyelamatkan. ${ }^{58}$

Mengenai cara atau metode pekabaran Injil, khususnya di Mamasa, tentu dipengaruhi juga oleh asas-asas pI di atas. Dalam asas ke-5 disebutkan, sebagai berikut: "Kita dapat mendekati bangsa itu dengan memakai sarana percakapan tercetak, selebaran-selebaran, polemik menentang kepercayaan mereka yang keliru, kumpulan nyanyian serta doa, dan kita dapat menyerahkan Alkitab ke dalam tangannya. Maka itu, pengajaran membaca secara besar-besaran harus dianggap salah satu persiapan yang jitu."59

52 Charles van Engen, Mission on the Way (Grand Rapids: Baker Books, 1996), 22-23.

53 Dean S. Gilliland, "Contextual Theology as Incarnational Mission", dalam The Word among Us: Contextualizing for Mission Today (London: Word Publishing, 1989), 28-29.

54 Van Engen, Mission on the Way, 19.

55 Thedorus Kobong, Injil dan Tongkonan: Inkarnasi, Kontekstualisasi, Transformasi, terj. Thedorus Kobong dan Th. van den End (Jakarta: BPK Gunung Mulia, 2008), 200.

56 Bnd. Theodorus Kobong, Iman dan Kebudayaan (Jakarta: BPK-Gunung Mulia, 1994), v.

57 Th. Kobong, "Kita Percaya”, dalam PENINJAU, tahun ke IX No. 1, (1982), 37.

58 Ibid.

${ }^{59}$ Van den End, Sumber-Sumber Zending..., 147. 
Dari asas itu, para penginjil pada abad ke-19 sampai medio abad ke-20 mengusahakan sarana pendidikan, penerjemahan Alkitab ke dalam bahasa setempat, surat-menyurat dan penerbitan majalah dll. Selain itu, asas ke-5 juga menyebutkan bahwa:

Dari sudut pandang lain, hal itu berlaku juga mengenai pengobatan dan perawatan orang sakit. Nabi-nabi, Kristus dan para Rasul telah memakai sarana itu pula. Dan dua sarana itu dianjurkan juga oleh bapa-bapa Gereja Gereformeerd kita, karena memandangnya sebagai sarana yang ampuh untuk disambut orang dan mendapat kesempatan bergaul dengan mereka .... Kita mengusahakannya pula secara teratur dengan mendirikan rumah sakit-rumah sakit, dengan mengutus dokter-dokter dan menyediakan tenaga perawat untuk perawatan orang sakit. Hanya, orang tetap harus memperhatikan benar bahwa semua itu merupakan persiapan dan sarana bantuan, bukan pekabaran Injil. ${ }^{60}$

Oleh karena itu, pelayanan medis adalah metode yang umum di kalangan badan misi dan utusan Injil, khususnya di kalangan Gereja Gereformeerd. Bahkan pelayanan medis telah mendahului pekabaran Injil di Korea. Pelayanan itu menjadi pembuka jalan bagi penginjilan dari badan misi Gereja Prebiterian dan Gereja Metodis di Korea. Pada asas itu juga ditekankan status pelayanan medis dan pelayanan lainnya yang bukan merupakan pekabaran Injil sebagai pelayanan pokok (hoofddienst) tetapi pelayanan pendukung/bantuan (hulpdienst). Tentu hulpdienst tersebut tidak boleh melemahkan kemandirian gereja yang telah berdiri sebagai hasil penginjilan badan zending tertentu. Apa yang terjadi di Gereja Toraja Mamasa (GTM), buah penginjilan ZCGK, adalah contoh ketidakmampuan gereja mengubah struktur dasar cara berpikir mereka untuk memahami makna masa lalu. Sampai saat ini (setelah 100 tahun Injil masuk Mamasa), bantuan finansial secara penuh dan tenaga pembina untuk pokok-pokok ajaran GTM masih diharapkan dari CGK; akibatnya GTM seperti gereja yang tidak percaya diri mengelola potensi sumber daya alam dan sumber daya manusia yang ada. ${ }^{61}$

Bertolak dari prinsip "berpikir dan bertindak historis sekaligus teologis", ${ }^{62}$ maka kejadian sejarah penginjilan di Mamasa dan India hendaknya mengubah struktur dasar cara berpikir kita untuk memahami makna masa lalu sekaligus menjawab pertanyaan teologis berikut ini:63 (1) Apa yang Allah katakan, kerjakan dan kehendaki di dalam dan melalui peristiwa itu?; (2) Apakah yang dilakukan manusia (dalam hal ini: gereja) dalam

60 Ibid.

61 Sampai saat ini, masih ada pendeta GTM yang mendapat gaji di bawah Rp. 500.000 per bulan. Oleh karena itu, jumlah pendeta GTM yang berusaha menjadi Pegawai Negeri Sipil meningkat, dibuktikan dengan adanya "25 pendeta GTM yang ikut tes CPNS Kategori II tahun 2013 ini” (Sonny K. (pegawai Kemenag Mamasa), wawancara oleh penulis, Jakarta, 9 November 2013).

62 Jan S. Aritonang, Berpikir dan Bertindak Historis Sekaligus Teologis: Pidato Pengukuhan dalam Jabatan Guru Besar Sejarah Gereja pada Sidang Terbuka Senat Sekolah Tinggi Teologi Jakarta, Sabtu, 11 Juni 2011 (Jakarta: UPI STT Jakarta, 2011), 10-11.

63 Ibid. 
menjawab apa yang Allah katakan dan kehendaki itu?; dan (3) Bagaimana manusia (gereja) mempertanggungjawabkan pemikiran, sikap dan tindakannya terhadap Allah maupun terhadap dunia dan sesamanya?

Tentu respons gereja terhadap tindakan Allah yang menyelamatkan, sesuai dengan zamannya. Pada abad ke-19 sampai medio abad ke-20 misalnya, para penginjil menyebut penganut agama pribumi sebagai kafir. Pada waktu itu, para penginjil Barat masih menganggap diri selalu benar dan bebas dari kelemahan atau dosa. ${ }^{64}$ Penginjil dari kaum Evangelikal masih meneruskan paham tersebut. Misiolog Evangelikal Jerman, Georg Friedrich Vicedom (1903-1974) ${ }^{65}$, misalnya, membagi dua dunia yaitu dunia yang dikuasai Iblis (Kerajaan Iblis) dan dunia yang dikehendaki Allah (Kerajaan Allah) yang keduanya saling berhadap-hadapan. Menurutnya, agama-agama lain (termasuk pagan) melakukan kesalahan yang ringan dan merugikan diri mereka sendiri. Karena itu, proklamasi Injil adalah jalan untuk menyingkapkan pengetahuan tentang Allah sebagai pencipta dan Tuhan, yang darinya manusia dapat berharap untuk ditebus dari dosa dan dunia. ${ }^{66}$

Sekarang ini, tentu pemahaman dan wawasan sudah lebih luas, sehingga istilah kafir tidak lagi dikenakan bagi penganut agama non-Kristen, tetapi disebut sebagai sesama umat beragama. Bahkan teologi religionum telah menjadi bagian dari kurikulum pendidikan di Sekolah-sekolah Teologi. Akan tetapi, metode pekabaran Injil pada abad ke19 sampai medio abad ke- 20 juga telah menolong kehidupan sosial-ekonomi masyarakat atau negara yang diinjili, sehingga taraf kehidupan mereka semakin maju.

Metode dialog dengan semua komponen masyarakat pribumi ternyata telah dikembangkan oleh badan zending dan penginjil abad ke-19 dan khususnya abad ke-20 (misalnya dialog Bikker dengan penganut Alu' toyolo di Mamasa, dialog Van Alphen dengan penganut agama Islam di Sumba, dialog dr. Allen dengan Pangeran Mien di Korea, dll.) Dialog dalam pekabaran Injil sangat perlu dan penting sebagai cara terbaik bagi gereja untuk mengabarkan Injil dalam dunia yang religius dan dalam budaya plural. Dialog yang dimaksud adalah mendengarkan dan berbicara. Dasarnya adalah missio Dei, misi Allah sendiri, yang dilakukan dengan komunikasi Ilahi yang dialogis dan relasional, baik dalam hidup ilahi sendiri (ad intra) (sejauh telah diwahyukan kepada umat Kristen melalui

${ }^{64}$ David J. Bosch, Transformasi Misi Kristen: Sejarah Teologi Misi yang Mengubah dan Berubah, terj. Stephen Suleeman (Jakarta: BPK Gunung Mulia, 1997), 560.

65 Georg F. Vicedom, The Mission of God, transl. by. Gilbert A. Thiele \& Dennis Hilgendorf (Saint Louis: Concordia Publishing House, 1965), 15-16.

66 Ibid. 
Yesus) maupun dalam karya Allah dalam dan melalui ciptaan (ad extra); di situ ada komunikasi dan tidak pernah berlangsung satu arah. ${ }^{67}$

Konteks merupakan bahan dialog global dalam penginjilan seperti yang diungkapkan Kim, bahwa hendaknya misiologi menjadi benar-benar global tetapi juga kontekstual sehingga "the whole church bringing the whole Gospel to the whole world". ${ }^{6}$ Dialog dalam pekabaran Injil harus yang bersifat profetis ${ }^{69}$, yaitu dialog yang tidak pernah dilakukan dalam ruang hampa melainkan dalam konteks tertentu. Dialog inilah yang terusmenerus dikembangkan pada masa sekarang terutama antar umat beragama.

Hasil dari "berpikir dan bertindak historis sekaligus teologis" antara lain perkembangan paradigma misi gereja-gereja Asia. Paradigma misi berkembang setelah IMC (International Missioanary Council) lahir dan berkonferensi pertama di Yerusalem pada tahun 1928), ${ }^{70}$ juga Life and Work Movement, dan Faith and Order Movement. Faith and Order Movement didirikan dengan tujuan menciptakan suasana baik untuk membangun diskusi teologis antargereja tentang ajaran dan tata gereja pada setiap konferensi. Life and Work Movement bertujuan memajukan kerjasama antara orang-orang Kristen dan gereja-gereja dalam bidang sosial dan politik, serta memajukan perdamaian dan saling pengertian antara bangsa-bangsa dan gereja-gereja. ${ }^{71}$ Mulai saat itu, pekabaran Injil bukan hanya kepada bangsa-bangsa lain, tetapi juga diarahkan kepada kesatuan ajaran dan tata gereja serta ikut mengusahakan kesejahteraan dan perdamaian dunia, kehidupan sosial, dan hubungannya dengan sesama manusia.

Konferensi IMC ke-3 di Tambaran tahun 1938 dengan tema "misi se-Dunia dari gereja" dalam pengaruh PD I (1914-1918) tidak sebatas membahas misi ke bangsa-bangsa lain tetapi bagaimana tanggapan gereja terhadap konflik dunia dan menggiring peserta konferensi untuk menyebarkan dan mewujudkan nilai-nilai Kristen dalam kehidupan sosial dan politik. ${ }^{72}$ Misi diarahkan pada berbagai pengalaman akan karya Kristus yang menyelamatkan manusia.

67 Paul F. Knitter, Menggugat Arogansi Kekristenan (terj.) (Yogyakarta: Penerbit Kanisius, 2005), 273274.

$68 \mathrm{Kim}$, Missiology as Global Conversation ..., 4.

69 Bevans, B. Stephen dan Schroeder P. Roger, Constants in Context: A Theology of Mission for Today (New York, Orbis Book, 2004), 4.

70 Ibid., 13-14.

${ }^{71}$ C. de Jonge, Pembimbing ke dalam Sejarah Gereja (Jakarta: BPK Gunung Mulia, cet. ke-9 2004), 8788: "Konferensi pertama Faith and Order Movement dilakukan di Lausanne (Swiss) tahun 1927 dan Konferensi pertama Life and Work Movement diadakan di Stockholm tahun 1925."

72 Richard A.D. Siwu, Misi: dalam Pandangan Ekumenikal dan Evangelikal Asia 1910-1961-1991 (Jakarta: BPK Gunung Mulia, 1966), 37-38. 
Menurut de Jonge ${ }^{73}$, prasejarah Life and Work Movement telah dimulai sejak abad ke XIX. Pada masa itu banyak organisasi Kristen dari berbagai gereja telah bekerjasama untuk melibatkan diri dalam aksi-aksi sosial di berbagai tempat. Salah seorang pelopornya adalah J. H. Wichern (1808-1881). Wichern adalah seorang pekabar Injil dalam negeri yang memulai gerakan kekristenan praktis pada dua bidang, yaitu sosial-ekonomi dan perdamaian internasional. Di bidang sosial-ekonomi, diusahakan perubahan-perubahan struktural dalam masyarakat sesuai dengan gagasan-gagasan Kristen, dan fokusnya adalah mengatasi ketidakadilan sosial-ekonomi. Tokoh-tokoh yang dapat disebutkan dalam gerakan ini antara lain Hermann Kutter (1869-1931) dan Leonhard Ragaz (1868-1945) dari gerakan sosialisme Kristen Swiss, dan Walter Rauschen-busch (1861-1918) dari gerakan Social Gospel di Amerika Serikat. Di bidang perdamaian internasional diusahakan menonjolkan peranan bersama gereja-gereja dalam mencari penyelesaian persoalanpersoalan politik. ${ }^{74}$

Gerakan-gerakan tersebut di atas bergabung dalam suatu wadah yang lebih luas, yaitu World Alliance of Churches for Promoting International Friendship yang didirikan tahun 1914 di London, Inggris. Melalui World Alliance inilah Soderblom mengusulkan dibentuknya Life and Work Alliance dengan menghubungkannya dengan keesaan. ${ }^{75}$ Kebijakan reformulasi misi tidak boleh mengabaikan pengenalan mendalam atas konteks misi (lapangan misi). Karena itu, muncullah ungkapan let's leave the theologians to it and get down to business, dengan melihat inkarnasi Kristus dalam misteri dan fakta inkarnasi. ${ }^{76}$ Menurut Richard Siwu, Konferensi Prapat (1957) menandai dua hal penting dalam kehidupan gereja-gereja Asia: pertama, gereja-gereja Asia semakin sadar akan kemandirian misi di Asia, dan kedua, makin menyadari bahwa keesaan dalam Kristus harus dimanifestasikan lewat misi bersama. ${ }^{77}$ Di Prapat mulai terlihat lima persoalan yang dihadapi Asia yaitu kemiskinan, ketidakadilan sosial, tingkat pendidikan dan kesehatan yang sangat rendah dan bentuk-bentuk kepercayaan seperti tahyul, maut, setan-setan dalam berhadapan dengan kekristenan. ${ }^{78}$ Masalah-masalah yang dihadapi Asia adalah persoalan-persoalan kehidupan berupa ketidakadilan, pelanggaran hak-hak azasi manusia,

${ }^{73}$ C. de Jonge, Menuju Keesaan Gereja (Jakarta: BPK Gunung Mulia, cet.ke-6 2006), 19.

74 Ibid., 27-28.

75 De Jonge, Menuju Keesaan Gereja, 29.

${ }^{76}$ Norman Goodall, "Willingen-Milestone, Not Terminus" dalam Missions Under the Cross (London: Edinburgh House Press, 1953), 11-13.

77 Siwu, Misi dalam Pandangan Ekumenikal dan Evangelikal Asia 1910-1961-1991, 168.

78 Komisi Pekabaran Injil D.G.I., Gereja-gereja Asia Timur Bertemu di Prapat (Djakarta: Badan Penerbit Kristen, 1957), 12-13. 
pertumbuhan penduduk yang cepat, kemiskinan, kekerasan, konflik, keterbelakangan dan orang-orang tersisih serta hubungan antara agama-agama lain. Semua persoalan tersebut disebabkan oleh pembangunan, industrialisasi dan modernisasi yang tidak sehat.

Di tingkat nasional (Indonesia), oleh DGI/PGI pada Sidang Raya tahun 1950, 1953, 1956, soal-soal masyarakat sudah diperhatikan, hanya saja gereja masih menghadapi kondisi sosial-politik yang menggoncangkan , sehingga perlu dicari format maupun pola baru bagi gereja untuk melaksanakan panggilannya (misinya) di tengah dunia. ${ }^{79}$ Pemikiran teologis orang Kristen dari negara tertentu juga mengalami peningkatan karena perjumpaan gereja Barat dengan konteks budaya mereka. Di Indonesia, termasuk di Mamasa dan Sumba, perjumpaan itu berlangsung melalui beberapa metode, yakni: penerjemahan Alkitab, penelitian etnografi dan antropologi dan melalui pendidikan. Dan pada masa empat puluh tahun pertama abad ke-20, berdirilah sekolah-sekolah guru di Indonesia, dan misi yang berbasis seminari-seminari. ${ }^{80}$

Dengan adanya perjumpaan dengan metode-metode (khususnya pendidikan) tersebut di atas maka lahirlah teolog-teolog dan pemimpin gereja di Indonesia yang handal pada paruh pertama abad ke-20. Mereka, antara lain Jerobeam Mattheus (ca. 1885-1944) di Jawa Timur, Todoeng Soetan Goenoeng Mulia (1896-1996) dari Sumatra Utara, Johannes Leimena (1905-1977) dari Maluku, dll. ${ }^{81}$

Di India, lahir juga teolog-teolog mutakhir dan berjasa dalam pengembangan teologi kontekstual. Mereka antara lain, A. J. Appasamy (1942), M.M. Thomas yang sangat memperhatikan keadaan sosial di India, V. Chakkarai dan P. Chenchiah (1930), dan Sadhu Sundar Singh (meninggal tahun 1929). ${ }^{82}$

\section{Kesimpulan}

Pentingnya pekabaran dan pekabar Injil telah disampaikan Paulus dalam Roma 10:14-15, "Bagaimana mereka dapat percaya kepada Dia, jika mereka tidak mendengar tentang Dia? Bagaimana mereka mendengar tentang Dia, jika tidak ada yang memberitakan-Nya?" Oleh karena itu, pertama-tama yang harus dipahami adalah penginjilan sebagai pekerjaan Allah (missio Dei). Allah sebagai Allah yang adil dan Maha Bijaksana berkenan memakai manusia supaya Ia didengar dipercaya semua ciptaan-Nya

${ }^{79}$ Karel Ph. Erari, Supaya Engkau Membuka Belenggu Kemiskinan (Jakarta: BPK Gunung Mulia, 1994), 15

80 John M. Prior dan Alle Hoekema, "Pemikiran Teologis oleh Orang Kristen Indonesia" dalam A History of Christianity in Indonesia, 750-756.

81 Ibid., 760.

82 Van den End, Sejarah Gereja Asia, 67-69. 
sebagai Allah yang berbicara, mendengar, melihat, membaui dan berbelas kasihan. ${ }^{83}$ Tetapi pemberita Injil adalah manusia dengan kebudayaannya yang telah dicemari dosa. Mereka pergi memberitakan Injil bukan hanya membawa Injil tetapi juga kebudayaan mereka, kebudayaan Eropa dan/atau Amerika.

Setiap badan zending dan orang yang memberitakan Injil berusaha menyajikan berita Injil dengan istilah-istilah termasuk metode yang dapat cocok dan dipahami oleh pendengarnya, yang relevan dengan budaya dengan kata lain mengkontekstualisasikan Injil. Memang, penginjilan yang baik dan alkitabiah adalah penginjilan yang kontekstual (misiologi kontekstual) dalam perjumpaan lintas budaya.

Dalam Alkitab Perjanjian Lama (PL), ditemukan beberapa contoh perjumpaan lintas budaya dalam hal suatu berita keagamaan, misalnya dalam politik (Yos 9; 1 Raj 15:16-22), agama (Hak 6:31-32; 1 Raj 18:1-40), perdagangan (2 Taw 8:17-18; 9: 21; Yeh 27:12-25), seni (Yeh 23:11-21). Dalam kitab Yeremia 29, Yeremia menganjurkan kepada bangsa Israel suatu adaptasi yang disengaja pada konteks negara Babel di mana mereka dibuang, sebagai yang tidak jauh dari pemahaman modern tentang kontekstualisasi. ${ }^{84}$ Akan tetapi dalam PL, perjumpaan-perjumpaan lintas budaya seperti itu, belum bisa dikategorikan sebagai penginjilan seperti pada masa Perjanjian Baru (PB).

Alkitab PB juga memberikan beberapa contoh perjumpaan-perjumpaan lintas budaya ketika orang-orang percaya perdana bergumul untuk melakukan transisi kepada budaya-budaya lain. Ada perjumpaan di bidang politik (Kisah Para Rasul 16:19-40), agama dan filsafat (Kisah Para Rasul 17:16-34), sihir (Kisah Para Rasul 13:4-12) dan ekonomi (Kisah Para Rasul 19:23-41). Bahkan ada kegiatan sastra oleh orang yang berusaha mengkontekstualisasikan pemberitaannya. Oleh karena itu, masing-masing kitab Injil, misalnya, mencerminkan kebudayaan penulisnya dan jelas ditujukan kepada sidang pembaca yang khusus. ${ }^{85}$ Sebagai contoh kontekstualisasi di dalam PB adalah pendekatan Paulus kepada masalah-masalah linguistik dan budaya di Listra (Kis. 14: 8-20).

Dengan demikian, sumber misiologi kontekstual adalah Allah sendiri yang berbicara dan mengilhami umat-Nya, pada zaman PL, PB, jemaat mula-mula, para penginjil sesudah itu, dan sampai sekarang. Pekerjaan Yesus yang memberitakan Kerajaan Allah pada konteks Yudaisme dan Romawi dapat dikatakan sebagai puncak missio Dei yang

\footnotetext{
83 Ebenhaizer I. Nuban Timo, Allah yang Mengulang Dirinya Tiga Kali: Suatu Pertimbangan bagi Dogmatika Kontekstual di Indonesia (Salatiga: Satya Wacana University Press, 2013), 170-202.

84 David J. Hesselgrave \& Edward Rommen, Kontekstualisasi: Makna, Metode dan Model, terj. Stephen Suleeman, (Jakarta: BPK Gunung Mulia, cet. ke-6 2009), 21.

85 Ibid., 25.
} 
kontekstual. Oleh karena itu, Paulus mengajak, agar kita mempunyai pikiran dan perasaan Kristus (Filipi 2:5) dalam berbagai aspek pemberitaan Injil. Kita sebagai Gereja, yang mewakili dan melanjutkan karya Allah di dunia ini, tidak bisa berbuat lebih atau kurang dari yang telah dikerjakan Allah dalam Yesus Kristus di dunia ini. Yesus menamakan manusia itu sahabat, bukan hamba (Yohanes 15:13-15). Paulus mengartikulasikan itu secara lebih konkret dengan menyebut dirinya kawan sekerja Allah (1 Korintus 3:9). Ia juga menyerukan orang percaya untuk mengerjakan keselamatan dengan takut dan gentar (Filipi 2:12), menjaga agar kerajinan jangan kendor (Roma 12:11) dan selalu giat dalam pekerjaan Tuhan (I Korintus 15:58). Dengan ayat-ayat Alkitab itu, manusia tetap bertanggung jawab dalam evangelisasi untuk menerangi dan membaharui manusia sebagaimana adanya seperti yang Yesus telah lakukan.

\section{Referensi}

\section{Buku yang Telah Diterbitkan}

Abineno, J.L.Ch. Kraemer di Tambaram. Jakarta: BPK Gunung Mulia, 1988.

Aritonang, Jan S. Berpikir dan Bertindak Historis Sekaligus Teologis: Pidato Pengukuhan dalam Jabatan Guru Besar Sejarah Gereja pada Sidang Terbuka Senat Sekolah Tinggi Teologi Jakarta, Sabtu, 11 Juni 2011. Jakarta: UPI STT Jakarta, 2011.

Bevans, Stephen, B. \& Roger, Schroeder P. Constants in Context: A Theology of Mission for Today. New York: Orbis Book, 2004.

Buijs, Kees. Powers of Blessing from the Wilderness and from Heaven: Structure and Transformation in the Religion of the Toraja in the Mamasa area of South Sulawesi. Leiden: KITLV Press, 2006.

Bosch, David J. Transformasi Misi Kristen: Sejarah Teologi Misi yang Mengubah dan Berubah, terj. Stephen Suleeman. Jakarta: BPK Gunung Mulia, 1997.

Bigalke, Terance W. Tana Toraja: A Social History of an Indonesian People. Leiden: KITLV Press, 2005.

Deputaten voor de Zending der Christelijke Gereformeerde Kerken Nederland. Pergilah Kamoe! Gaat dan Heen! Geschiedenis van de Buitenlandse Zending der Christelijke Gereformeerde Kerken Nederland tot 1959. Dodrecht: D.J. van Brummen, 1960.

Menuju Keesaan Gereja. Jakarta: BPK Gunung Mulia, cet.ke-6, 2006.

End, Th. van den. Sejarah Gereja Asia. Yogyakarta: PPIP Dutawacana, cet. ke-2 1988.

Sumber-sumber Zending tentang Sejarah Gereja Kristen Sumba 1859-1972 (terj.). Jakarta: BPK Gunung Mulia, 1996.

Harta dalam Bejana. Jakarta: BPK Gunung Mulia, cet. ke-17, 2004.

End, Th. van den \& Weitjens, J. Ragi Carita 2: Sejarah Gereja di Indonesia, Jakarta: BPK Gunung Mulia, cet. ke-3 1999.

End, Th. van den \& de Jong, Chris G.F. "Christianity in Central and Southern Sulawesi, " dalam A History of Christianity in Indonesia, ed. J. S. Aritonang \& Karel Steenbrink. Leiden \& Boston: Brill, 2008.

Engen, Charles van, Mission on the Way. Grand Rapids: Baker Books, 1996.

Erari, Karel Ph. Supaya Engkau Membuka Belenggu Kemiskinan. Jakarta: BPK Gunung Mulia, 1994. 
Gilliland, Dean S. "Contextual Theology as Incarnation Mission", dalam The Word among Us: Contextualizing for Mission Today. London: Word Publishing, 1989.

Goodall, Norman. "Willingen-Milestone, Not Terminus", dalam Missions Under the Cross. London: Edinburgh House Press, 1953.

Hesselgrave David J. \& Rommen, Edward. Kontekstualisasi: Makna, Metode dan Model, terj. Stephen Suleeman. Jakarta: BPK Gunung Mulia, cet. ke-6 2009.

Hunt, Everett N. Jr. Protestant Pioneers in Korea. Maryknoll, New York: Orbis Books, 1980. Jonge, C. de. Pembimbing ke dalam Sejarah Gereja. Jakarta: BPK Gunung Mulia, cet. ke-9, 2004.

Menuju Keesaan Gereja. Jakarta: BPK Gunung Mulia, cet.ke-6 2006.

Klies, W.A. van der. Datanglah Kerajaan-Mu: Lima Puluh Tahun Pekabaran Injil di Toraja Barat 1913-1969. Rantepao: Sulo, 2006.

Kobong Th. Alu', Adat dan Kebudayaan Toraja dalam Perjumpaan dengan Injil. TangmentoE: Institut

Theologia Indonesia, 1992.

Iman dan Kebudayaan. Jakarta: BPK-Gunung Mulia, 1994.

"Kita Percaya", dalam PENINJAU, tahun ke IX No. 1, 1982.

Knitter, Paul F. Menggugat Arogansi Kekristenan (terj.).Yogyakarta: Kanisius, 2005.

Komisi Pekabaran Injil D.G.I. Gereja-gereja Asia Timur Bertemu di Prapat. Djakarta: Badan Penerbit Kristen, 1957.

Moffett, Hugh Samuel. A History of Christianity in Asia, Vol. II 1500-1900. Maryknoll, New York: Orbis Books, 2005.

Persekutuan Gereja-gereja di Indonesia. Buku Almanak Kristen Indonesia 2013. Jakarta: Bidang Kononia PGI, 2013.

Ruck, Anne. Sejarah Gereja Asia. Jakarta: BPK Gunung Mulia, 1997.

Siwu, Richard A.D. Misi dalam Pandangan Ekumenikal dan Evangelikal Asia 1910-19611991. Jakarta: BPK Gunung Mulia, 1996.

Timo Nuban, Ebenhaizer I. Allah yang Mengulang Dirinya Tiga Kali: Suatu Pertimbangan bagi Dogmatika Kontekstual di Indonesia. Salatiga: Satya Wacana University Press, 2013.

Vicedom, Georg F. The Mission of God, transl. Gilbert A. Thiele \& Dennis Hilgendorf. Saint Louis: Concordia Publishing House, 1965.

Wellem, F.D. "The Unequal Fight Between Traditional Religion and Christianity in Sumba", dalam A History of Christianity in Indonesia. ed. J. S. Aritonang \& Karel Steenbrink. Leiden \& Boston: Brill, 2008.

Wetzel, Klaus. Kompendium Sejarah Gereja Asia. Malang: Gandum Mas, 2000.

\section{Tesis dan Disertasi}

Abialtar. Katekismus Heidelberg di Gereja Toraja Mamasa: Menyoal Kontekstualisasi Katekismus Heidelberg dalam Konteks Pergumulan Budaya dan Oikumenis Gereja Toraja Mamasa. STT Jakarta: Tesis M.Th., 2008.

Wellem, F.D. Injil dan Marapu: Suatu Studi Historis Teologis tentang Perjumpaan Injil dengan Masyarakat Sumba pada Periode 1876-1990. STT Jakarta, Disertasi D.Th., 1995.

\section{Artikel}


Kirsteen, Kim. Missiology as Global Conversation of (Contextual) Theologies. STT Jakarta: Artikel Bahan Test Kualifikasi S-3, 2012.

\section{Makalah Ceramah}

Gunawan, Hengky. “Kepemimpinan GTM abad XXI.” Ceramah, Aula BPMS-GTM, Mamasa, 8 Juli 2011.

\section{Wawancara}

K. Sonny. (pegawai Kemenag Mamasa). Wawancara oleh penulis. Jakarta, 9 November 2013.

Mahine, Ambe (pemimpin Aluk Toyolo). Wawancara oleh penulis. Mamasa, 18 Juli 2012. Mandadung, A. Wawancara oleh penulis. Mamasa, 26 November 2010. 